\title{
Hubungan Tingkat Pengetahuan dan Dukungan Sosial Terhadap Self-Care Behavioral pada Pasien Hemodialisis dengan Atriovenous Fistula dan Double Catheter Lumen
}

\author{
Oliva Suyen Ningsih ${ }^{1 *}$, Heribertus Handi ${ }^{1}$, Lidwina Dewiyanti Wea ${ }^{1}$, Dorothea \\ Nasvia ${ }^{1}$, Karolus Fransiskus Tono ${ }^{1}$. \\ 1 Universitas katolik Indonesia Santu Paulus Ruteng, Indonesia \\ *Korespondensi: osningsih@gmail.com
}

\begin{tabular}{|c|c|}
\hline & \multirow{7}{*}{ 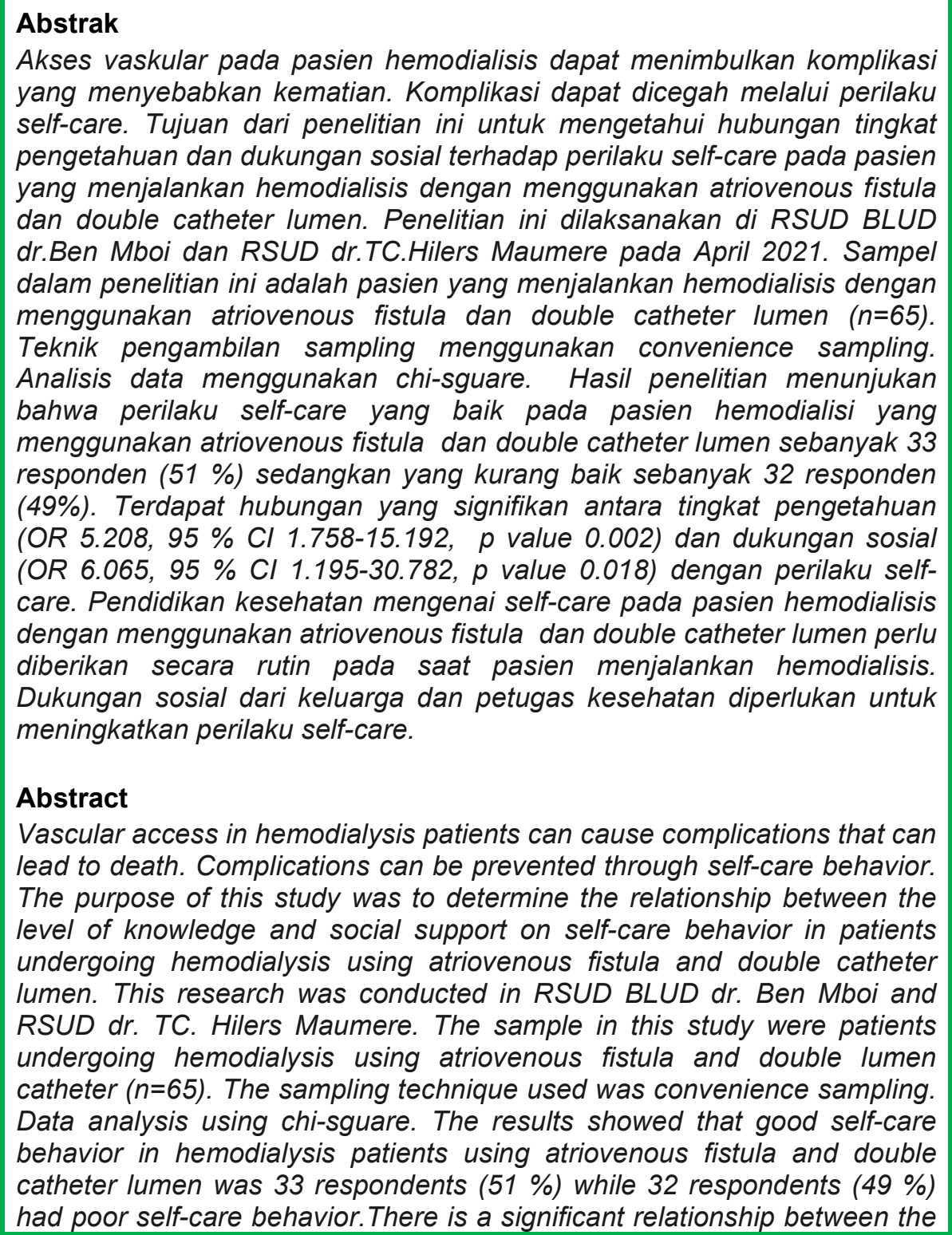 } \\
\hline & \\
\hline & \\
\hline & \\
\hline & \\
\hline & \\
\hline & \\
\hline
\end{tabular}


level of knowledge (OR 5.208, $95 \%$ Cl 1.758-15.192, p value 0.002) and social support (OR 6.065, $95 \%$ Cl 1.195-30.782, $p$ value 0.018) with selfcare behavior. Health education about self-care in hemodialysis patients needs to be given routinely to patients every time they carry out hemodialysis. Social support from families and health workers is needed to improve self-care behavior.

\section{Pendahuluan}

Penyakit gagal ginjal stadium akhir merupakan masalah kesehatan global khususnya di negara-negara berpenghasilan rendah-menengah yang memberikan dampak serius bagi individu dan keluarga misalnya dalam bidang sosial dan ekonomi (Costa Pessoa et al., 2020; Sousa et al., 2014). Di Amerika Serikat pada tahun 2016, sebanyak 126.000 (2 orang dari setiap 1.000 orang) yang hidup dengan transplantasi ginjal dan dialisis (CDC, 2019). Di Indonesia, pasien dengan gagal ginjal stadium akhir meningkat dua kali lipat yaitu $0.38 \%$, dibandingkan dengan tahun 2013 yang hanya mencapai 0,2 \% dan yang menjalankan terapi hemodialisis sebanyak 19,3\% (Kementerian Kesehatan Republik Indonesia, 2018). Berdasarkan Riskesdas (2018),prevalensi gagal ginjal kronis berdasarkan diagnosis Dokter pada penduduk umur $\geq 15$ tahun di Propinsi Nusa Tenggara Timur,sebesar $0.33 \%$ dan yang menjalankan hemodialisis sebanyak $9.94 \%$. Di kabupaten Manggarai, prevalensi gagal ginjal kronis sebesar $0,15 \%$ dan di kabupaten Sikka sebanyak 0,30 \% (Tim Riskesdas, 2019)

Hemodialisis adalah salah satu metode terapi yang digunakan untuk pengobatan gagal ginjal stadium akhir. Pasien gagal ginjal stadium akhir akan menjalankan hemodialisis seumur hidup untuk mempertahankan hidupnya (Purba et al., 2018). Akses vaskular pada pasien gagal ginjal tahap akhir yang menjalankan hemodialisis sangat diperlukan antar lain Doubel Catheter Lumen (DCL) dimana kateter diimplantasi pada vena sentral dan Arteriovenosus Fistula (AVF) . DCL menjadi pilihan pertama pada pengobatan karena dapat digunakan segera setelah implantasi dan dapat digunakan pada pasien untuk jangka waktu beberapa hari hingga bulan sementara pasein menunggu pembuatan atau pematangan akses vaskular seperti AVF (Maia et al., 2019). AVF memiliki keuntungan antara lain menyediakan aliran darah yang baik untuk dialisis, bertahan lebih lama dan menurunkan morbiditas dan mortalitas dibandingkan dengan atriovenosus grafts dan central venous catheter (Costa Pessoa et al., 2020; Yang et al., 2019)

Akses vaskuler pada pasien yang menjalankan hemodialisis baik menggunakan AVF maupun DCL dapat menimbulkan komplikasi.Meskipun tingkat komplikasi lebih rendah pada AVF, komplikasi dapat terjadi melalui akses vaskular tersebut yang dapat mengancam kehidupan. Komplikasi yang dapat terjadi antara lain iskemia pada tangan, trombosis, edema, perdarahan, dan sindrom carpal tunnel (Adib-Hajbagheri et al., 2014). Sebuah systematic review melaporkan bahwa, rata-rata tingkat komplikasi per 1000 pasien per hari yang menggunakan AVF adalah 0.04 untuk aneurisma, 0,11 untuk infeksi, dan 0,24 untuk trombosis (Costa Pessoa et al., 2020). Sementara itu, penggunaan kateter vena seperti DCL untuk hemodialis dapat meningkatkan angka morbiditas dan mortalitas yang tinggi pada pasien dengan gagal ginjal tahap akhir. Salah satu komplikasi yang paling sering terjadi adalah infeksi, yang kejadiannya bervariasi sesuai dengan jenis kateter, lamanya waktu, teknik, dan tempat pemasangan, serta perawatan dan 
pemeliharaan yang dilakukan oleh tenaga perawat. Di Brasil, infeksi terkait kateter untuk hemodialisis berkisar antara 3,2 hingga 40,4 kejadian per seribu hari penggunaan kateter dan angka kematian terkait berkisar dari 6,7 hingga $75,0 \%$ (Maia et al., 2019)

Komplikasi pada pasien gagal ginjal tahap akhir yang menjalankan hemodialisis menggunakan AVF dan DCL dapat dicegah melalui perilaku self-care. Perilaku self-care didefinisikan sebagai semua perilaku yang dilakukan oleh pasien gagal ginjal tahap akhir untuk menjaga dan meningkatkan kesehatan serta fungsi AVF dan DCL selama hemodialisis (Costa Pessoa et al., 2020; Maia et al., 2019; Sousa et al., 2014). Adib-Hajbagheri (2014) melaporkan bahwa terdapat hubungan yang signifikan antara self-care pasien dan terjadinya komplikasi AVF. Berdasarkan studi awal terhadap pasien yang menjalankan haemodialisis menggunakan AVF dan DCL di BLUD RSUD Dr.ben Mboi, sebagian besar pasien belum mengetahui perilaku self-care yang harus dilakukan untuk meningkatkan kesehatan dan menjaga fungsi AVF dan DCL agar terhindar dari komplikasi. Penelitian sebelumnya hanya mengkaji perilaku self-care pada pasien yang menjalankan hemodialisis dengan menggunakan AVF tanpa mengkaji faktor-faktor apa saja yang mempengaruri perilaku self care pada pasien yang menjalankan hemodialisis dengan menggunakan AVF dan DCL. Penelitian ini penting dilakukan untuk mengetahui hubungan tingkat pengetahuan dan dukungan sosial terhadap perilaku self- care pada pasien yang menjalankan hemodialis dengan menggunakan AVF dan DCL. Penelitian yang dilakukan oleh (Diab \& Mostafa, 2019) menunjukan sebagain besar responden (78 \%) yang menjalankan hemodialisis dengan menggunaakan AVF memiliki perilaku self-care yang buruk. Berdasarkan studi awal pada pasien yang menjalankan hemodialisis menggunakan AVF dan DCL di BLUD RSUD dr Ben Mboi menunjukkan sebagian besar (50 \%) memiliki perilaku self-care yang buruk. Hasil penelitian ini dapat berkontribusi terhadapa intervensi lebih lanjut untuk meningkatkan perilaku selfcare pada pasien yang menjalankan hemodialis dengan menggunakan AVF dan DCL sehingga dapat mengurangi terjadinya komplikasi dan dapat menurunkan morbiditas dan mortalitas pada pasien gagal ginjal tahap akhir yang menjalankan hemodialisis.

\section{Metode Penelitian}

Penelitian ini merupakan penelitian kuantitatif dengan desain penelitian cross sectional yang bertujuan untuk mengetahui hubungan tingkat pengetahuan dan dukungan sosial dengan perilaku self- care pada pasien yang menjalankan hemodialis dengan menggunakan AVF dan DCL. Penelitian ini di laksanakan di RSUD BLUD dr.Ben Mboi dan di RSUD dr.TC.Hilers Maumere pada bulan AprilJuni 2021. Populasi dalam penelitian ini adalah semua pasien yang menjalankan hemodialisis dengan menggunakan AVF dan DCL. Sampel dalam penelitian ini adalah pasien yang menjalankan hemodialisis menggunakan AVF dan DCL yang memenuhi kriteria inklusi. Kriteri inklusi adalah pasien gagal ginjal kronik yang telah menjalankan hemodialisis minimal 1 bulan dengan menggunakan AVF atau $\mathrm{DCL}$, usia $\geq 18$ tahun dan kesadaran komposmentis. Kriteria eksklusi adalah pasien hemodialisis dengan gangguan kognitif. Teknik pengambilan sampling dengan menggunakan convenience sampling dengan jumlah sampel 65 responden dari 105 populasi. 
Instrumen yang digunakan dalam penelitian ini berupa kuisioner yang terdiri dari: identititas responden, kuisioner self- care pada pasien yang menjalankan hemodialis dengan menggunakan AVF dan DCL, kuisioner pengetahuan dan dukungan sosial. Identitas responden meliputi nama (initial), usia, jenis kelamin, status perkawinan, penididikan terakhir, pekerjaan, lama cuci darah, akses hemodialisis, informasi perawatan AVF dan DCL, jadwal cuci darah. Kuisioner self- care pada pasien yang menjalankan hemodialis dengan menggunakan AVF berisi tentang perilaku pencegahan komplikasi dan perilaku manejemen tanda dan gejala pada pasien yang menjalankan hemodialis dengan menggunakan AVF dengan total 18 item pertanyaan (Yang et al., 2019). Kuisioner self- care pada pasien yang menjalankan hemodialis dengan menggunakan DCL berisi tentang perilaku pencegahan komplikasi dan perilaku manajemen tanda dan gejala pada pasien yang menjalankan hemodialis dengan menggunakan DCL dengan total 12 item pertanyaan (Maia et al., 2019).

Hasil uji validitas kuisioner self- care pada pasien yang menjalankan hemodialis dengan menggunakan AVF dan DCL dengan Cronbach's alpha 0.712 dan uji realibilitas dengan korelasi pearson menunjukkan $r$ hitung $>r$ tabel. Kuisioner pengetahuan berisi tentang konsep hemodialisis, komplikasi dan masalah terkait hemodialisiis, perawatan AVF dan DCL dengan total 18 item pertanyaan (Fadlalmola \& Elkareem, 2020). Hasil uji validitas kuisioner pengetahuan dengan Cronbach's alpha 0.708 dan hasil uji validitas dengan korelasi pearson menunjukkan $r$ hitung $>r$ tabel . Kuisioner dukungan sosial berisi tentang dukungan dari keluarga dan petugas kesehatan (dokter dan perawat) pada pasien yang menjalankan hemodialis dengan menggunakan AVF dan DCL (Fadlalmola \& Elkareem, 2020; Maia et al., 2019; Sukmawati, 2018). Hasil uji validitas kuisioner dukungan sosial dengan Cronbach's Alpha 0.861 dan hasil uji validitas dengan korelasi pearson menunjukkan $r$ hitung $>r$ tabel. Analisis data menggunakan analisis deskriptive statistics dengan menggunakan chisguare. Sebelum analisis bivariat, dilakukan uji normalitas dan homogenitas. Uji normalitas menunjukkan data tidak berdistribusi normal. Hal ini kemungkinan karena kategori data baik pada variabel dependen maupun variabel independen merupakan data kategorik. Hasil Penelitian ini telah mendapatkan persetujuan etik dari komisi etik Universitas Katolik Indonesia Santu Paulus Ruteng dengan no.05a/SK-IIla/Warek I02/k/02/2021

\section{Hasil}

Tabel 1. Karakteristik responden yang menjalankan hemodialisis dengan

\begin{tabular}{|c|c|c|c|}
\hline No & Variabel & $\mathrm{n}$ & $\%$ \\
\hline \multirow[t]{3}{*}{1} & Jenis kelamin : & & \\
\hline & Laki-laki & 39 & 60 \\
\hline & wanita & 26 & 30 \\
\hline \multirow[t]{4}{*}{2} & Lama hemodialisis & & \\
\hline & $<1$ tahun & 20 & 31 \\
\hline & $1-5$ tahun & 41 & 63 \\
\hline & $>5$ tahun & 4 & 6 \\
\hline \multirow[t]{3}{*}{3} & Akses hemodialysis & & \\
\hline & AVF & 53 & 82 \\
\hline & DCL & 12 & 18 \\
\hline
\end{tabular}




\begin{tabular}{lllr}
\hline 4 & $\begin{array}{l}\text { Frekuensi } \\
\text { Hemodialisis }\end{array}$ & & \\
\hline 1x/minggu & 4 & 6 \\
\hline $2 x /$ minggu & 58 & 89 \\
\hline $3 x /$ minggu & 3 & 5 \\
\hline
\end{tabular}

Berdasarkan tabel 1. karakterstik responden yang menjalankan hemodialis dengan menggunakan AVF dan DCL sebagian besar berjenis kelamin laki-laki yaitu sebanyak 39 responden (60\%), lama hemodialysis 1-5 tahun sebanyak 41 responden $(63 \%)$, akses hemodilisis menggunkan AVF sebanyak 53 responden $(82 \%)$ dan frekuensi hemodialisis $2 x /$ minggu sebanyak 58 responden $(89 \%)$.

Tabel 2. Hubungan antara tingkat pengetahuan dan perilaku self-care pada pasien hemodialisis yang menggunakan AVF dan DCL $(n=65)$

\begin{tabular}{|c|c|c|c|c|c|c|c|c|c|c|}
\hline \multirow{3}{*}{$\begin{array}{l}\text { Variabel } \\
\text { Pengetahuan }\end{array}$} & \multicolumn{4}{|c|}{ Perilaku self -care } & \multicolumn{2}{|c|}{ Total } & \multirow[t]{3}{*}{ OR } & \multicolumn{2}{|c|}{$94 \% \mathrm{Cl}$} & \multirow{3}{*}{$\begin{array}{l}P \\
\text { value }\end{array}$} \\
\hline & \multicolumn{2}{|c|}{$\begin{array}{l}\text { Kurang } \\
\text { Baik }\end{array}$} & \multicolumn{2}{|c|}{ Baik } & \multirow[t]{2}{*}{$\mathrm{n}$} & \multirow[t]{2}{*}{$\%$} & & \multirow[t]{2}{*}{ Lower } & \multirow[t]{2}{*}{ Upper } & \\
\hline & $\mathrm{n}$ & $\%$ & $\mathrm{n}$ & $\%$ & & & & & & \\
\hline Rendah & 20 & 31 & 8 & 12 & 28 & 53 & 5.208 & 1.758 & 15.192 & 0.002 \\
\hline Tinggi & 12 & 18 & 25 & 39 & 37 & 57 & & & & \\
\hline Total & 32 & 49 & 33 & 51 & 65 & 100 & & & & \\
\hline
\end{tabular}

Tabel 2. menunjukkan hasil analisis bivariat dengan menggunakan chisguare yaitu terdapat hubungan yang signifikan antara tingkat pengetahuan dan perilaku self-care pada pasien hemodialisis yang menggunakan AVF dan DCL (OR $5.208,95 \%$ Cl 1.758-15.192, p value 0.002). Berdasarkan hasil OR, responden dengan tingkat pengetahuan yang rendah berrisiko 5.208 kali lipat memiliki perilaku self-care yang kurang baik.

Tabel 3. Hubungan antara dukungan sosial dan perilaku self-care pada pasien hemodialisis yang menggunakan AVF dan DCL $(\mathrm{n}=65)$

\begin{tabular}{|c|c|c|c|c|c|c|c|c|c|c|}
\hline \multirow{3}{*}{$\begin{array}{l}\text { Variabel } \\
\text { Dukungan } \\
\text { Sosial }\end{array}$} & \multicolumn{4}{|c|}{ Perilaku self -care } & \multicolumn{2}{|c|}{ Total } & \multirow[t]{3}{*}{ OR } & \multirow{3}{*}{$\begin{array}{l}94 \% \mathrm{Cl} \\
\text { Lower }\end{array}$} & \multirow{3}{*}{\multicolumn{2}{|c|}{$\begin{array}{cc} & \mathrm{P} \\
\text { Upper } & \text { value }\end{array}$}} \\
\hline & \multicolumn{2}{|c|}{$\begin{array}{l}\text { Kurang } \\
\text { Baik }\end{array}$} & \multicolumn{2}{|c|}{ Baik } & \multirow[t]{2}{*}{$\mathrm{n}$} & \multirow[t]{2}{*}{$\%$} & & & & \\
\hline & $\mathrm{n}$ & $\%$ & $\mathrm{n}$ & $\%$ & & & & & & \\
\hline Rendah & 9 & 14 & 2 & 3 & 11 & 17 & 6.065 & 1.195 & 30.782 & 0.018 \\
\hline Tinggi & 23 & 35 & 31 & 48 & 54 & 83 & & & & \\
\hline Total & 32 & 49 & 33 & 51 & 65 & 100 & & & & \\
\hline
\end{tabular}

Tabel 3 menunjukkan hasil analisis bivariat dengan menggunakan chi-sguare yaitu terdapat hubungan yang signifikan antara dukungan sosial dan perilaku selfcare pada pasien hemodialisis yang menggunakan AVF dan DCL (OR 6.065, $95 \%$ $\mathrm{Cl}$ 1.195-30.782, p value 0.018). Berdasarkan hasil OR, responden dengan dukungan sosial yang rendah berrisiko 6.065 kali lipat memiliki perilaku self-care yang kurang baik.

\section{Pembahasan}

Hasil penelitian menunjukan bahwa sebagai besar responden yang menjalankan hemodialisis dengan menggunakan AVF dan DCL memiliki perilaku self-care yang baik dan sebagain lagi memiliki perilaku self-care yang kurang baik. Hasil penelitian ini sesuai dengan penelitian yang dilakukan oleh (Sousa et al., 2020) yang menunjukkan bahwa sebanyak 63,9 \% pasien hemodialisi yang menggunakan AVF memiliki perilaku yang kurang baik dalam manajemen 
komplikasi dan sebanyak $82,8 \%$ memiliki perilaku self- care yang kurang baik dalam manajemen tanda dan gejala.

Self-care adalah suatu proses mengelolah kesehatan melalui aktivitas yang dapat meningkatkan kesehatan, monitoring perawatan diri dan manajemen perawatan diri.Self-care sangat diperlukan oleh pasien gagal ginjal tahap akhir yang menjalankan hemodialisis baik menggunakan AVF maupun DCL untuk mencegah terjadinya kompliksi (Yang et al., 2019). Sebuah systematic review melaporkan bahwa, rata-rata tingkat komplikasi per 1000 pasien per hari yang menggunakan AVF adalah 0.04 untuk aneurisma, 0,11 untuk infeksi, dan 0,24 untuk trombosis (Costa Pessoa et al., 2020). Sementara itu, penggunaan kateter vena seperti DCL untuk hemodialis dapat meningkatkan angka morbiditas dan mortalitas yang tinggi pada pasien dengan gagal ginjal tahap akhir. Salah satu komplikasi yang paling sering terjadi adalah infeksi, yang kejadiannya bervariasi sesuai dengan jenis kateter, lamanya waktu, teknik, dan tempat pemasangan, serta perawatan dan pemeliharaan yang dilakukan oleh tenaga perawat.

Perilaku self-care pada pasien hemodialisis dengan menggunkan AVF dan DCL meliputi perilaku pencegahan komplikasi dan manajemen tanda dan gejala. Beberapa faktor yang dapat mempengaruhi pasien hemodilasis dengan menggunakan AVF dan DCL dalam melakukan self-care adalah usia dan tingkat pendidikan, dukungan sosial, dan pengetahuan. Usia dan tingkat pendidikan berhubungan signifikan dengan self-care pada individu dewasa yang menjalankan hemodialisis dengan p value 0.018 dan 0.031 (Han \& Kim, 2016) Ind.ividu yang menjalankan hemodialis dengan tingkat pendidikan sekolah dasar dan menengah memiliki self-magement yang rendah dari pada individu dengan tingkat pendidikan diploma atau diatasnya (Gela \& Mengistu, 2018).

Hasil penelitian kami menunjukkan pengetahuan berhubungan signifikan dengan perilaku self-care pada pasien hemodialisis dengan menggunkan AVF dan DCL. Pasien yang memiliki tingkat pengetahuan yang rendah cenderung untuk tidak melakukan self-care dengan baik dibandingkan dengan pasien yang memiliki pengetahuan yang tinggi. Hal ini didukung oleh penelitian yang dilakukan oleh (Gela \& Mengistu, 2018) yang menyatakan bahwa individu dengan tingkat pengetahuan yang rendah 5.5 kali berisiko memiliki perilaku self-management yang rendah dalam menjalankan hemodialisis dibandingkan dengan individu dengan tingkat pendidikan yang tinggi.Pengetahuan individu yang rendah mengenai hemodialisis menggunakan AVF dan DCL berdampak pada perilaku self-care yang rendah terhadap AVF dan DCL. Pendidikan kesehatan mengenai perilaku self-care terhadap AVF dan DCL sangat diperlukan oleh pasien hemodialisis untuk dapat meningkatkan pengetahuannya (Pessoa \& Linhares, 2015). Pengetahuan yang meningkat mengenai self-care dapat mengkatkan kesadaran pasien untuk mengubah perilaku dan melakukan self-care secara mandiri. Pendidikan self-care yang diperlukan pasien hemodialisis yang menggunakan AVF dan DCL mencakup pencegahan komplikasi dan manajemen tanda dan gejala.

Faktor lain yang mempengaruhi perilaku self-care pada pasien hemodialisis dengan menggunkan AVF dan DCL adalah dukungan sosial. Individu yang memiliki dukungan sosial yang rendah baik dukungan dari keluarga maupun dari petugas kesehatan cenderung memiliki perilaku self-care yang rendah dibandingkan dengan individu yang memiliki dukungan sosial yang tinggi. Hasil 
penelitian ini didukung oleh penelitian yang dilakukan oleh (Kim \& Kim, 2019) yang menyebutkan bahwa terdapat hubungan yang signifikan antara dukungan sosial dengan self-care pasien yang menjalankan hemodialiasis. Pada individu dengan penyakit kronik termasuk pasien dengan gagal ginjal tahap akhir yang menjalankan hemodialis sangat membutuhkan dukungan yang berasal dari anggota keluarga, petugas kesehatan, teman, dan tetangga. Dukungan yang diberikan dapat mempengaruhi kondisi psikologi pada pasien yang menjalankan hemodialis dengan Atriovenous Fistula dan Doubel Catheter Lumen.

Dukungan yang dapat diberikan oleh keluarga pada pasien yang menjalankan hemodialisis dengan menggunakan AVF dan DCL seperti menolong saat pasien mengalami kesakitan akibat proses penyakit yang dialami, mengantarkan pasien saat hemodialisis, mengingatkan pasien jadwal hemodialisis, mendampingi pasien saat merasa putus asa dan depresi karena penyakit yang dialami. Penelitian yang dilakukan oleh (Kim \& Kim, 2019) menunjukkan bahwa sebagian besar pasien yang menjalankan hemodialisis mengalami depresi sedang dan berat yang mempengaruhi self- care. Oleh karena itu sangat diperlukan dukungan sosial dari keluarga pada pasien yang menjalankan hemodialisis untuk mengurangi depresi yang dapat mempengaruhi self-care. Dukungan yang dapat diberikan oleh petugas kesehatan pada pasien yang menjalankan hemodialisis dengan menggunakan AVF dan DCL seperti memberikan informasi mengenai penyakit yang dialami, tujuan hemodialisis, efek samping dan perawatan akses vaskuler hemodialisis baik menggunakan AVF dan DCL dan menunjukkan perhatian serta sikap caring pada pasien yang sedang menjalankan hemodialisis secara khusus ketika pasien mengalami keluhan.

\section{Kesimpulan}

Pengetahuan dan dukungan sosial sangat berpengaruh terhadap perilaku self-care pada pasien hemodialisis yang menggunakan AVF dan DCL . Individu yang memiliki pengetahuan dan dukungan sosial yang rendah cendrung memiliki perilaku self-care yang kurang baik terhadap AVF dan DCL. Pendidikan kesehatan mengenai self-care pada pasien hemodialisa dengan menggunakan atriovenous fistula dan double catheter lumen perlu diberikan secara rutin pada pasien setiap kali menjalankan hemodialisa sesuai dengan karakteristik pasien. Dukungan sosial dari keluarga dan petugas kesehatan diperlukan untuk meningkatkan perilaku selfcare.

Penelitian selanjutnya disarankan untuk meneliti pengaruh intervensi pendidikan kesehatan dan faktor lainnya terhadap perilaku self-care pada pasien hemodialisis dengan menggunakan atriovenous fistula dan double catheter lumen.

\section{Ucapan Terima Kasih}

Terima kasih kepada seluruh responden yang telah bersedia terlibat dalam penelitian ini. Ucapan terima kasih juga kepada Unit Penelitian dan Pengabdian Kepada Masyarakat (UPPM) Universitas Katolik Indonesia Santu Paulus Ruteng yang telah memberikan dukungan biaya penelitian.

\section{Daftar Pustaka}

Adib-Hajbagheri, M., Molavizadeh, N., Alavi, N. M., \& Abadi, M. H. M. (2014). Factors associated with complications of vascular access site in hemodialysis patients in Isfahan Aliasghar hospital. Iranian Journal of Nursing and 
Midwifery Research, 19(2), 208-214. http://www.ncbi.nlm.nih.gov/pubmed/24834093\%0Ahttp://www.pubmedcentral .nih.gov/articlerender.fcgi?artid=PMC4020033

CDC. (2019). Chronic Kidney Disease in the United States, 2019. https://www.cdc.gov/kidneydisease/publications-resources/2019-nationalfacts.html

Costa Pessoa, N. R., de Souza Soares Lima, L. H., dos Santos, G. A., de Queiroz Frazão, C. M. F., Sousa, C. N., \& Ramos, V. P. (2020). Self-care actions for the maintenance of the arteriovenous fistula: An integrative review. International Journal of Nursing Sciences, 7(3), 369-377. https://doi.org/10.1016/j.jijnss.2020.06.007

Diab, T. M., \& Mostafa, N. M. (2019). Self-Care Behaviors for Arteriovenous Fistula among Hemodialysis Patients at Assiut University Hospital (Suggested Nursing Brochure ). 7(1), 87-92. https://doi.org/10.12691/ajnr-7-1-12

Fadlalmola, H. A., \& Elkareem, E. M. A. (2020). Impact of an educational program on knowledge and quality of life among hemodialysis patients in Khartoum state. International Journal of Africa Nursing Sciences, 12(February), 1-4. https://doi.org/10.1016/j.ijans.2020.100205

Gela, D., \& Mengistu, D. (2018). Self-management and associated factors among patients with end-stage renal disease undergoing hemodialysis at health facilities in Addis Ababa, Ethiopia. International Journal of Nephrology and Renovascular Disease, 11, 329-336. https://doi.org/10.2147/JJNRD.S184671

Han, S. J., \& Kim, H. W. (2016). Factors influencing self-care behaviors in elderly hemodialysis patients. International Journal of Bio-Science and BioTechnology, 8(6), 31-38. https://doi.org/10.14257/ijbsbt.2016.8.6.04

Kementerian Kesehatan RepublikIndonesia. (2018). Hasil Utama Riskesdas 2018. https://www.kemkes.go.id/resources/download/info-terkini/hasil-riskesdas2018.pdf

Kim, B., \& Kim, J. (2019). Influence of uncertainty, depression, and social support on self-care compliance in hemodialysis patients. Therapeutics and Clinical Risk Management, 15, 1243-1251. https://doi.org/10.2147/TCRM.S218934

Maia, S. F., Facundes, D. M., \& Carneiro, A. L. L. (2019). Patient self-care with double catheter lumen for hemodialization: Validation of instructional folder. Acta Scientiarum - Health Sciences, 41(1), 2-7. https://doi.org/10.4025/actascihealthsci.v41i1.47558

Pessoa, N. R. C., \& Linhares, F. M. P. (2015). Hemodialysis patients with arteriovenous fistula: knowledge, attitude and practice. Escola Anna Nery Revista de Enfermagem, 19(1), 73-79. https://doi.org/10.5935/14148145.20150010

Purba, A. K., Emaliyawati, E., \& Sriati, A. (2018). Self-Management and SelfEfficacy in Hemodialysis Patients. Journal of Nursing Care, 1(2), 129-139. http://jurnal.unpad.ac.id/jnc/article/view/16137/8271

Sousa, C. N., Marujo, P., Filipa, V., \& Dias, F. (2020). Self-Care Behavior Profiles With Arteriovenous Fistula in Hemodialysis Patients. Clinical Nursing 
Research ·, 29(6), 363-367. https://doi.org/10.1177/1054773818787110

Sousa, C. N., Teles, P., Filipa, V., Dias, F., Luís, J., Apóstolo, A., Henriqueta, M., Silva, J., \& Martins, M. M. (2014). Physical examination of arteriovenous fistula: The influence of professional experience in the detection of complications. Hemodialysis International, 18(3), 695-699. https://doi.org/10.1111/hdi.12170

Sukmawati, A. K. (2018). Analisis Faktor yang Berhubungan Dengan Penerimaan Diri Pasien Gagal Ginjal Kronis yang Menjalani Terapi Hemodialisa di Rumah Sakit Umum Haji Surabaya [Universitas Airlangga]. In Universitas Airlangga Surabaya. http://repository.unair.ac.id/85199/

Tim Riskesdas. (2019). Laporan Provinsi Nusa Tenggara Timur: Riskesdas 2018. https://www.litbang.kemkes.go.id/laporan-riset-kesehatan-dasar-riskesdas/

Yang, M. miao, Zhao, H. hua, Ding, X. qiang, Zhu, G. hong, Yang, Z. hua, Ding, L., Yang, X. hao, Zhao, Y., Chen, L., Yang, R. mei, Fang, J., \& Sousa, C. N. (2019). Self-Care Behavior of Hemodialysis Patients With Arteriovenous Fistula in China: A Multicenter, Cross-Sectional Study. Therapeutic Apheresis and Dialysis, 23(2), 167-172. https://doi.org/10.1111/1744-9987.12770 